\title{
Rapport annuel 2016
}

\section{La Commission de fondation de la Caisse de secours des médecins suisses}

Au cours de l'exercice écoulé, la Caisse de secours des médecins suisses a accordé son soutien à 16 médecins tombés malgré eux dans le besoin (ils étaient 15 en 2015) ainsi qu'aux proches et aux descendants de médecins décédés.

Une aide durable et deux aides uniques se sont ajoutées en 2016.

Les produits ont résulté des recettes provenant de dons pour un montant de CHF 31888.17 (2015: CHF 114405.90) ainsi que des intérêts et des dividendes du capital de la fondation, à hauteur de CHF 83228.02 (2015: CHF 86633.30).

Concernant les charges, les contributions de soutien que nous avons versées ont atteint le montant de CHF 156000.- (2015: CHF 132 000.-). Les dépenses relatives à la gestion de la Caisse de secours et à l'administration de la fortune se sont élevées à CHF 58 958.65.

La différence entre les recettes provenant de dons ainsi que des intérêts et dividendes du capital et les charges consécutives aux contributions de soutien et aux dépenses administratives a constitué un déficit de recettes de CHF 99996.95 imputé sur la fortune de la fondation.

Nous constatons malheureusement un recul massif des recettes issues des dons, dont les causes ne sont pas totalement explicables, mais pourraient être liées à l'envoi tardif des demandes de soutien - les mesures adéquates ont été prises. L'état toujours critique du rendement de la fortune de la fondation, tel qu'exposé dans un article paru récemment dans la Basler Zeitung (BaZ du 11.11.2017, page 7), nous préoccupe également. Dans ce contexte, la fondation est toujours fortement dépendante de dons généreux du corps médical suisse. Les dépenses de gestion et d'administration de la fortune peuvent sembler très élevées, mais elles sont nécessaires pour que la fondation soit solide et conforme aux directives - sans cela, nous ne pourrions pas satisfaire aux examens exigés d'office d'une fondation bénéficiant d'une exonération fiscale totale.

Les dons individuels inférieurs à CHF 500 forment le pilier traditionnel de notre fondation. Afin de réduire nos frais administratifs, nous renonçons à remercier personnellement les donateurs. Nous leur exprimons donc notre gratitude ici.
Les comptes annuels de la Caisse de secours ont été révisés par la société Martin Treuhand AG qui en a confirmé l'exactitude. Nous la remercions cordialement de son travail. Des informations détaillées sur les comptes annuels sont disponibles dans le bilan et le compte d'exploitation publiés ci-après.

La fortune de la fondation consiste en un mélange d'obligations et d'actions conforme aux prescriptions de la prévoyance professionnelle (LPP).

Le compte d'exploitation, le bilan et la gestion de la fortune sont examinés chaque année par l'autorité de surveillance LPP et des fondations des deux Bâles. L'activité du Conseil de fondation est bénévole. Je tiens à remercier tous les membres de la Commission pour le travail fourni l’an passé. Je remercie également Monsieur A. Billich de Notenstein La Roche Banque Privée SA pour la tenue de la comptabilité et la gestion de la fortune.

La Commission de fondation de la Caisse de secours des médecins suisses

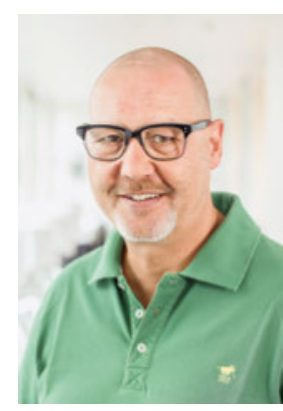

Dr U. Lüscher, président (photo) DrS. Stöhr

Dr U. Leibundgut, trésorier

Compte postal de la Caisse de secours des médecins suisses: 40-644-3 Bâle 


\section{Comptes annuels 2016}

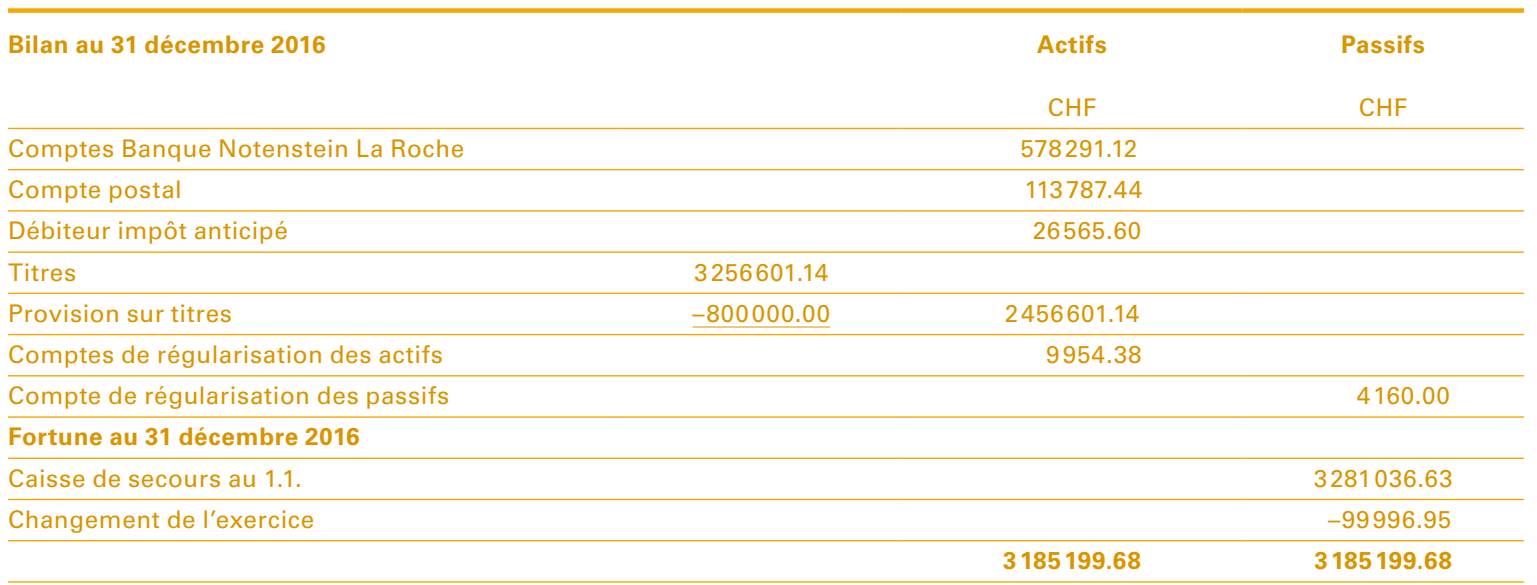

\begin{tabular}{lrr} 
& CHF & CHF \\
\hline Dons & 31888.17 \\
\hline Revenu sur capital & 83228.02 \\
\hline Ajustement provision sur titres & 36000.00 \\
\hline Ajustement change & 145.94 \\
\hline Perte sur titres (réalisée) & 36300.45 \\
\hline Contributions & 156000.00 \\
\hline Frais de banque & 22551.88 \\
\hline Frais d'administration & 36406.75 \\
\hline Perte de l'exercice & -99996.95 \\
\hline
\end{tabular}

